\title{
In situ TEM study of dislocation mobility in semiconducting materials
}
F. Louchet $\left({ }^{1}\right)$, J. Pelissier $\left({ }^{2}\right)$, G. Vanderschaeve $\left({ }^{4}\right)$
D. Caillard $\left.{ }^{3}\right)$,
J.P. Peyrade $\left({ }^{4}\right)$,
C. Levade $\left({ }^{4}\right)$ and

(1) LTPCM-ENSEEG, B.P. 75, 38402 St-Martin d'Hères Cedex, France

$\left({ }^{2}\right)$ Département de Métallurgie, CENG, Avenue des Martyrs, BP 85X, 38402 St-Martin d'Hères Cedex, France

$\left({ }^{3}\right)$ CEMES-LOE/CNRS, 29 rue Jeanne Marvig, B.P. 4347, 31055 Toulouse Cedex, France

$\left({ }^{4}\right)$ LPS-INSA, Complexe Scientifique de Rangeil, 31077 Toulouse Cedex, France

(Received January 29, 1993; accepted February 15, 1993)

Résumé . - Des expériences de déformation in situ de semiconducteurs élémentaires, et de composés III-V et II-VI, ont été réalisées à Toulouse et Grenoble. Cet article donne une interprétation commune des résultats obtenus, ce qui permet de discuter l'effet de la force des liaisons covalentes sur les mobilités des dislocations dans divers cas de figure.

\begin{abstract}
In situ straining experiments have been conducted in Toulouse and Grenoble on elemental semiconductors, III-V and II-VI compounds. This article gives a common interpretation of the results obtained, which allows us to discuss the effect of the strength of covalent bonding on the mobility of dislocations under different conditions.
\end{abstract}

\section{Introduction.}

The present paper deals with covalent and ionocovalent semiconductors with either a diamond cubic (DC) structure like elemental semiconductors ( $\mathrm{Si}, \mathrm{Ge})$, or a sphalerite structure like a number of compound semiconductors of the III-V type (In Sb, Ga As, In P) or of the II-VI type $(\mathrm{Zn} \mathrm{S})$. Due to covalent bonding, dislocations experience a strong lattice friction, which overwhelms elastic interactions, hinders collective effects, and results in a slow thermally activated motion of individual defects. These materials are then good candidates for investigating the mobility of individual dislocations, by complementary techniques [1] like etch pits, X-ray topography and in situ TEM straining experiments.

In other cases of lattice friction (e.g. non planar dissociation of screws in BCC structures), a linear dependence of velocities on dislocation lengths has been evidenced a long time ago (see for instance the film "living metals" by Imura). In contrast, in the present case, kinks experience a 
strong frictional force, which restricts the velocity of dislocations $(v)$ versus length $(L)$ to a limited range of lengths, up to a critical length $X$ which in some cases falls within the range observable in TEM. The particular rate equations for dislocation motion in this case have been proposed by Hirth and Lothe [2] and we shall show here that in situ experiments allow a thorough determination of the related activation parameters.

In some compound semiconductors, dislocation velocities are also influenced by the electron beam. TEM in situ experiments have also been used for investigating this so called cathodoplastic effect.

\section{Experimental techniques.}

Experimental results reviewed here have been obtained in Toulouse and Grenoble on microscopes operating at voltages between $200 \mathrm{kV}$ and $1 \mathrm{MV}$, on prestrained specimens. Dislocation velocities have been measured on video records, and stresses estimated from curvatures at dislocation bends [3]. The materials investigated in this study are listed in table I, as well as the corresponding experimental conditions.

Table I. - Materials investigated.

\begin{tabular}{|c|c|c|c|}
\hline Material & Temperature range & E.M. Voltage & References \\
\hline \multicolumn{4}{|l|}{ Elemental } \\
\hline$\cdot \mathrm{Si}$ & $520-615^{\circ} \mathrm{C}$ & $1 \mathrm{MeV}$ & [4] \\
\hline - $\mathrm{Ge}$ & $400-430^{\circ} \mathrm{C}$ & $400 \mathrm{kV}$ & [8] \\
\hline \multicolumn{4}{|l|}{ III-V } \\
\hline - InSb & $170^{\circ} \mathrm{C}-250^{\circ} \mathrm{C}$ & $200 \mathrm{kV}, 1 \mathrm{MV}$ & {$[9,10 \mathrm{a}, 12]$} \\
\hline - GaAs & $350^{\circ} \mathrm{C}$ & $200 \mathrm{kV}, 1 \mathrm{MV}$ & {$[10 \mathrm{a}, 10 \mathrm{~b}]$} \\
\hline •InP & $350^{\circ} \mathrm{C}$ & $200 \mathrm{kV}$ & [11] \\
\hline \multicolumn{4}{|l|}{ II-VI } \\
\hline$\cdot \mathrm{Zns}$ & $20^{\circ} \mathrm{C}-180^{\circ} \mathrm{C}$ & $200 \mathrm{kV}$ & $\begin{array}{l}\text { study of the cathodo- } \\
\text { plastic effect }[13,14,15]\end{array}$ \\
\hline
\end{tabular}

\section{Dislocation cores in the DC or sphalerite structures.}

In these structures, dislocations (of Burgers vector $a / 2<110>$ ) have a minimum core energy when aligned along the three $<110>$ directions of the (111) slip planes. Resulting hexagonal loops therefore consists in screw segments separated by 2 types of $60^{\circ}$ segments. There is now a reasonable evidence that dislocations belong to the glide set and not to the shuffle one [5], and are dissociated into Shockley partials which exhibit a $30^{\circ}$ or a $90^{\circ}$ character. 
Due to non centrosymmetry, $60^{\circ}$ dislocations in $\mathrm{AB}$ (e.g. Ga As) compound semiconductors are of two different types: core atoms are only of A (e.g. Ga) type in B dislocations, and of B (e.g. As) type in $\alpha$ dislocations. Bond reconstruction is then expected to be more difficult here than in elemental semiconductors [5].

As suggested by the core structure, the friction on kinks can be reasonably ascribed to a periodic potential $W_{\mathrm{m}}$ which is related to kink velocity by: [2]

$$
v_{\mathrm{k}}=\nu_{\mathrm{D}} b\left(\sigma b^{3} / k T\right) \exp \left(-W_{\mathrm{m}} / k T\right)
$$

and to the kink pair nucleation rate $J$ by:

$$
J=\left(\nu_{\mathrm{D}} / b\right)\left(\sigma b^{3} / k T\right) \exp \left(-\left(F+W_{\mathrm{m}}\right) / k T\right)
$$

where $\sigma$ is the stress, $\nu_{\mathrm{D}}$ the Debye frequency, and $F=F(\sigma)$ the saddle point energy for nucleating a kink pair of critical length

The resulting mean free path of a kink pair is: $\left({ }^{1}\right)$

$$
X=2\left(v_{\mathrm{k}} / J\right)^{1 / 2}=2 b \exp (F(\sigma) / 2 k T)
$$

and dislocation velocities have two asymptotic forms according to whether their lengths $L$ are large or small as compared to $X$ :

$$
\begin{aligned}
& L<<X: V=b J L=\nu_{\mathrm{D}}\left(\sigma b^{3} / k T\right) L \exp \left(-\left(F+W_{\mathrm{m}}\right) / k T\right) \\
& L>>X: V=b J X=2 \nu_{\mathrm{D}}\left(\sigma b^{4} / k T\right) \exp \left(-\left(F / 2+W_{\mathrm{m}}\right) / k T\right)
\end{aligned}
$$

\section{Results.}

4.1 DisLOCATION KINETICS AND ACTIVATION ENERGIES. - In all the studied materials, the movement of dislocations was observed to be smooth and continuous, indicating that they are submitted to a lattice frictional force. The temperature dependence of the dislocation shapes and velocities is illustrated in figure 1 , in the case of InSb strained at $170{ }^{\circ} \mathrm{C}$ and $230{ }^{\circ} \mathrm{C}$ : the lower the temperature, the lower the velocity in spite of a higher stress (as evidenced by a smaller radius of curvature at the dislocation bend).

In agreement with the Hirth and Lothe model [2], the transition between the two velocity regimes was evidenced for the first time in Si by in situ straining experiments $[4,6]$ and by in situ stress relaxation [7]. The critical length $X$ separating the two regimes was found around $0.4 \mu \mathrm{m}[4,6]$. More recently, velocity measurements in Ge showed that screws moved significantly faster than $60^{\circ}$ dislocations (Fig. 2), and a statistical analysis of the $V(L)$ dependence [8] yielded a mean free path $X$ between 0.6 and $1 \mu \mathrm{m}$ under the experimental conditions. More important, the combined measurements of the mean free path $X$ and of the dislocation velocities allowed a complete determination of the activation energies for kink migration $W_{\mathrm{m}}$ and for kink pair formation $F$ (Eqs. (3), (4) and (5)) (Tab. II). In silicon, the activation energy of the dislocation velocity has been directly measured in the length independent regime by an Arrhenius plot [4]. The value obtained $(\Delta G=1.9 \mathrm{eV} \pm 1 \mathrm{eV}$ for $\sigma=240 \mathrm{MPa})$ is in agreement with the results of table II, since $\Delta G=F / 2+W_{\mathrm{m}}$ according to equation (5). The formation energy of a single kink $F k$ has also been deduced from $F$ and $\sigma$ (see [8], for instance).

$\left({ }^{1}\right)$ This definition follows the theoretical work of Hirth and Lothe [2]. However in [9], $X$ was defined as the mean free path of a single kink, i.e. $X$ was one half of the value given in Table II. 

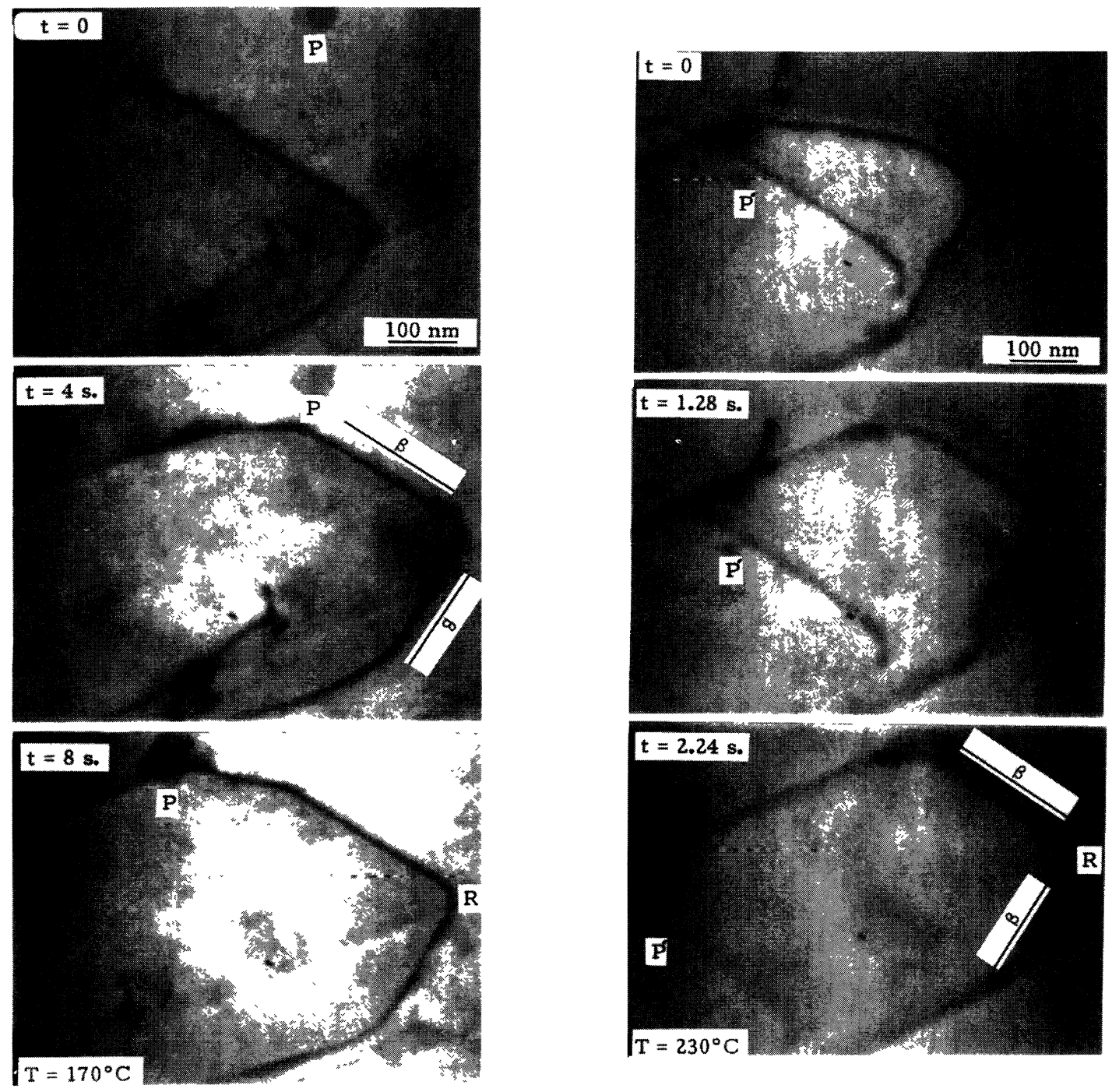

Fig. 1. - Dislocation movements in InSb. a) $T=170{ }^{\circ} \mathrm{C}$, b) $T=230{ }^{\circ} \mathrm{C}$. Same area as in a). Note the higher velocity and the lower stress (larger radius of curvature $R$ ). $P$ and $P^{\prime}$ are fixed points.

The dependence of dislocation velocity on dislocation character is much more pronounced in III-V compounds. Indeed, $\alpha$ dislocations move at a much higher velocity than screw and $B$ dislocations. Screw and $B$ dislocations have similar velocities, as shown in figure 3 for InSb [9] (note that in [9] the temperature was wrongly mentioned to be $180{ }^{\circ} \mathrm{C}$ instead of $250{ }^{\circ} \mathrm{C}$ ) and in figure 4 for InP [11] (see also [10a] for GaAs). At the same time, $X$ is much larger than in elemental semiconductors: using HVEM in situ experiments the length effect is indeed observed at least up to $3 \mu \mathrm{m}$ in GaAs (Fig. 5, [10]) and to $5 \mu \mathrm{m}$ in InSb [12] for screw dislocations (due to both the thin foil geometry and the elongated shape of the expanding dislocation loops, only screw 


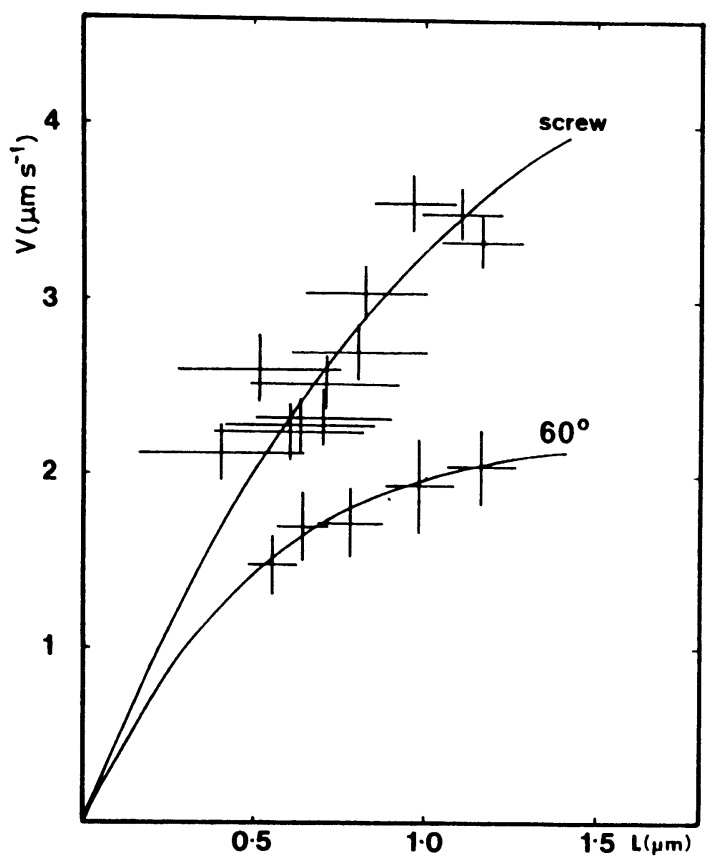

(a)

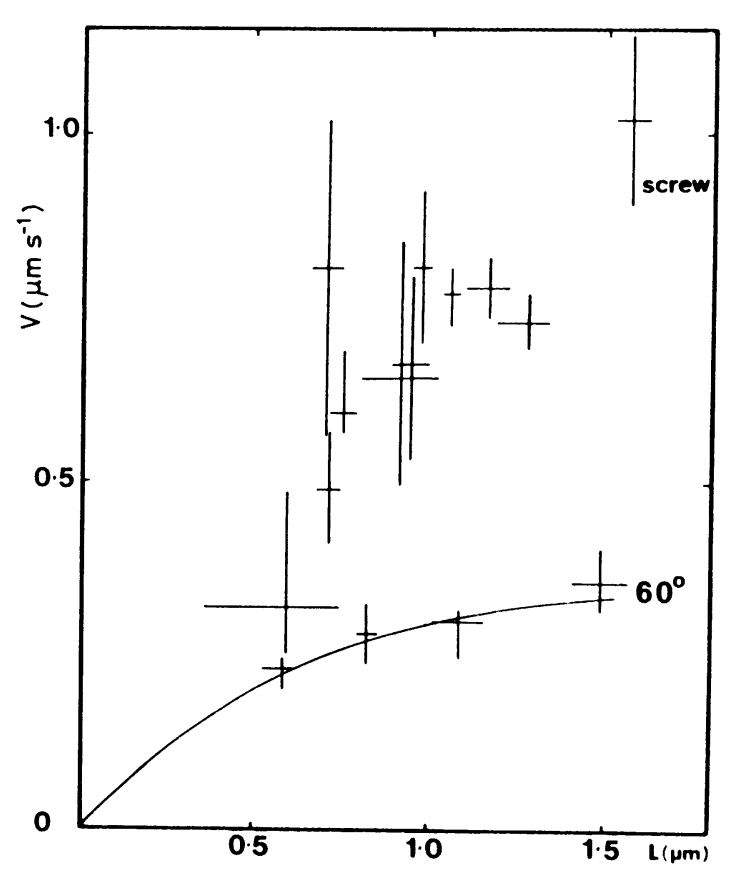

(b)

Fig. 2. - Diagram of dislocation velocities versus length in germanium showing the continuous transition between the two asymptotic length regimes (from [9]). a) $T=430{ }^{\circ} \mathrm{C}, \sigma=40 \mathrm{MPa}$; b) $T=405{ }^{\circ} \mathrm{C}$, $\sigma=35 \mathrm{MPa}$.

Table II. - Activation parameters for dislocation movements as determined from in situ TEM experiments. $(*)$. This value of $\mathrm{Fk}$ has been deduced from [6]. Note that is was wrongly estimated in $[8]$.

\begin{tabular}{|c|c|c|c|c|c|c|c|}
\hline Material & Dislocation & $\begin{array}{c}\text { Temperature } \\
\left({ }^{\circ} \mathrm{C}\right) \\
\end{array}$ & $\begin{array}{l}\text { Stress } \\
(\mathrm{MPa})\end{array}$ & $\begin{array}{c}X \\
(\mu \mathrm{m}) \\
\end{array}$ & $\begin{array}{l}F(\sigma) \\
(e V)\end{array}$ & $\begin{array}{l}\mathrm{Wm} \\
(\mathrm{eV}) \\
\end{array}$ & $\begin{array}{c}\mathrm{Fk} \\
(\mathrm{eV})\end{array}$ \\
\hline $\mathrm{Si}$ & $\begin{array}{l}60^{\circ} \\
+ \text { screw } \\
\end{array}$ & $\begin{array}{c}520-615 \\
540\end{array}$ & $\begin{array}{l}240 \\
550\end{array}$ & 0.4 & \begin{tabular}{|l}
1.2 \\
0.88 \\
\end{tabular} & $\begin{array}{l}1.3 \\
1.3 \\
\end{array}$ & $\begin{array}{l}0.9^{(*)} \\
\left.0.9^{*}\right) \\
\end{array}$ \\
\hline $\mathrm{Ge}$ & $\begin{array}{l}60^{\circ} \\
\text { screw } \\
\end{array}$ & $\begin{array}{l}430 \\
405 \\
\end{array}$ & $\begin{array}{r}40 \\
35 \\
\end{array}$ & $\begin{array}{l}0.55 \\
0.70 \\
\end{array}$ & $\begin{array}{l}0.79 \\
0.79 \\
\end{array}$ & $\begin{array}{l}0.86 \\
0.92 \\
\end{array}$ & $\begin{array}{l}0.50 \\
0.50 \\
\end{array}$ \\
\hline InSb & $\begin{array}{l}\text { Screw } \\
+60^{\circ} B \\
\end{array}$ & 250 & 50 & $>5$ & $0.8-1.2$ & $<0.4$ & $0.5-0.65$ \\
\hline InP & $\begin{array}{l}\text { Screw } \\
+60^{\circ} \mathrm{B} \\
\end{array}$ & 350 & 50 & $>0.7$ & $0.8-1.5$ & $<0.64$ & \\
\hline GaAs & $\begin{array}{l}\text { Screw } \\
+60^{\circ} \mathrm{B}\end{array}$ & 350 & 50 & $>3$ & $1.1-1.6$ & $<0.5$ & $0.65-0.9$ \\
\hline
\end{tabular}


segments can be long enough) Very fast radiation effects were however observed in HVEM [10b]. The same techniques as above can be applied for determining the activation energies. In this case, however, since $L<<X$, the activation energy for the velocity of dislocations is $\Delta G=F+W_{\mathrm{m}}$, according to equation (4). Since only a minimum value of $X$ has been measured, only a maximum value of $W_{\mathrm{m}}$ has been determined, whence a rather large uncertainly on $F(\sigma)$ and $F k$. A summary of the obtained results is given in Table II.

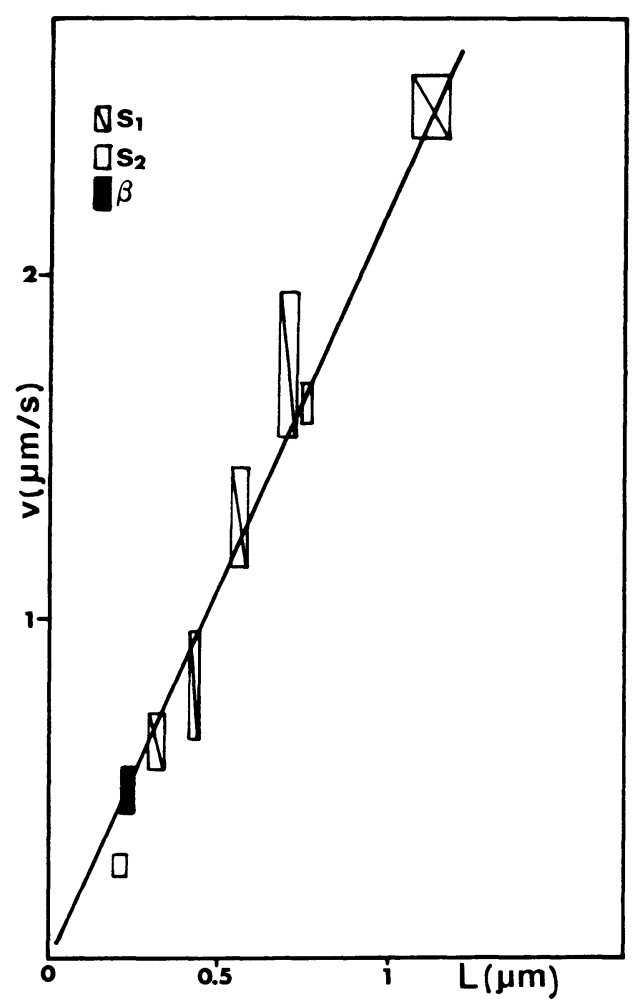

Fig. 3. - Length effect in InSb (from [10]). $T=250{ }^{\circ} \mathrm{C}$ (instead of $180^{\circ} \mathrm{C}$, as wrongly mentioned in [10]), $\sigma=50 \pm 15 \mathrm{MPa}$. $\beta$ refers to one type of $\beta$ segments, and $S_{1}, S_{2}$ refer to screw segments of opposite signs.

4.2 CATHODOPLASTIC EFFECT. - Under electron excitation, dislocation velocities in a variety of large band gap semiconductors are observed to increase [17]. This is known as the "cathodoplastic effect". The effect is rather weak in InSb and a little bit larger in GaAs at $350{ }^{\circ} \mathrm{C}$ [10a], but no quantitative measurements have been performed. A systematic investigation of this effect has been made on the II-VI compound $\mathrm{ZnS}[13,14,15]$. The main results of our study are:

i) the dependence of dislocation velocity on dislocation character is much less pronounced than in III-V compounds,

ii) the dislocation motion under electron excitation is still viscous and continuous, indicating that they are submitted to a lattice friction,

iii) at constant stress and electron-beam intensity, the velocity of a dislocation segment is proportional to its length. In the studied length range $(L<0.4 \mu \mathrm{m})$ no evidence of a saturation of 


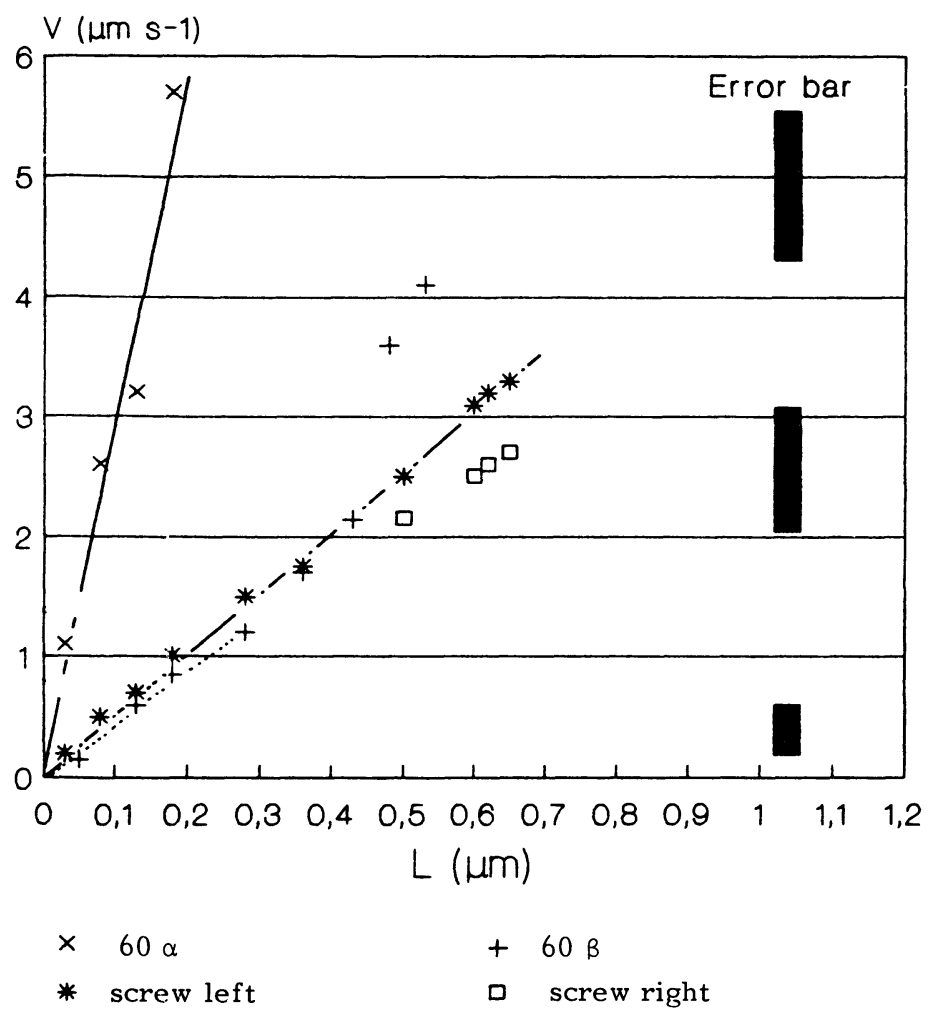

Fig. 4. - Length effect in InP (from [12]). $T=400{ }^{\circ} C, \sigma=55 \pm 10 \mathrm{MPa}$.

the dislocation velocities is observed (Fig. 6).

iv) the dislocation mobility is strongly enhanced by electron irradiation. Using a periodic deflecting beam apparatus, it is observed that at $T=180^{\circ} \mathrm{C}$, the dislocation velocity under electron excitation $(I=1000 \AA / \mathrm{m} 2)$ is about 2500 times greater than that "in darkness" $(I=\mathrm{O})$.

Figure 7 reports the variation of $P=\mathrm{d} V / \mathrm{d} L$ with $I$ at different temperatures. It is seen that at low intensity $P$ depends linearly on $I$, whereas at higher intensities $\mathrm{d} P / \mathrm{d} I$ decreases as $I$ increases.

\section{Discussion.}

The above results have been compared with results from other techniques. The stress dependence of dislocation velocities at different temperatures in silicon agree quite well with results of George [20] obtained by X-ray topography (Fig. 8), where all dislocation velocities have been measured in the length independent regime. In the case of $\mathrm{InSb}$ at $250^{\circ} \mathrm{C}$, the dislocation velocities measured by Erofeeva and Osip'Yan [21] on bent specimens by the double etch pits technique (Fig. 9), fit in with the dislocation velocity measured in situ on $1 \mu \mathrm{m}$ long dislocations. This probably indicates that the results of Erofeeva and Osip'Yan have been obtained on dislocation segments gliding in the length dependent regime.

The following main points result from dislocation velocity measurements: i) the mean free path of kinks measured on slow dislocations is much larger in compounds than in elemental semiconductors, ii) velocities of screws is larger than that of $60^{\circ}$ dislocations in $\mathrm{Ge}$ (and probably also in 

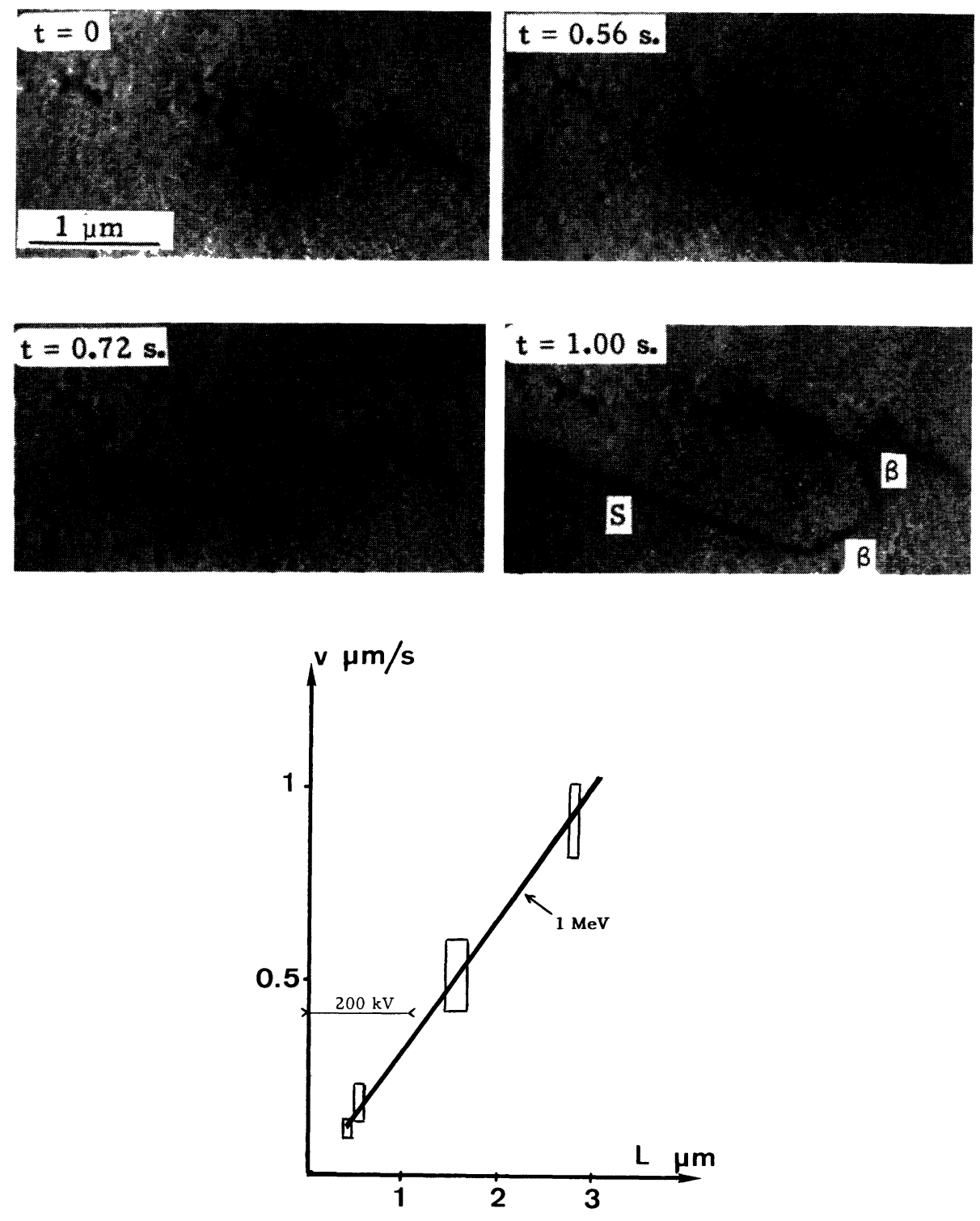

Fig. 5. - Length effect in a thick GaAs sample. HVEM measurement (from [11b]. a) loop expansion, b) velocity of the screw segment versus length. The domain of measurements at $200 \mathrm{kV}$ is indicated for comparison.

$\mathrm{Si})$, iii) velocities of $\alpha$ dislocations in III-V compounds are much larger than those of $\beta$ and screws.

The larger value of $X$ in compounds can be easily explained by a more difficult reconstruction of bonds in dislocation cores. Troughs of the migration potential of kinks which are rather shallow for non-reconstructed kinks become indeed deeper for reconstructed ones, since reconstruction lowers their energy at stable positions. $W_{\mathrm{m}}$ is then smaller in compounds, where kinks are not expected to reconstruct. Usually, during in situ experiments on different materials, the applied stress is implicitely adjusted in such a way that dislocation velocities are almost the same, i.e. are 


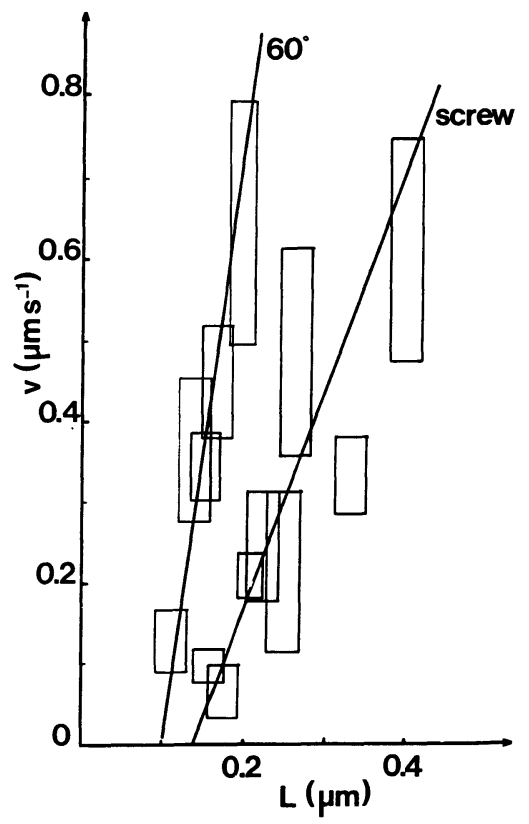

Fig. 6. - Length effect in $\mathrm{ZnS} . T=120^{\circ} \mathrm{C}, \sigma=40 \pm 10 \mathrm{MPa}$, beam intensity $I=5600 \AA / \mathrm{m}^{2}$.

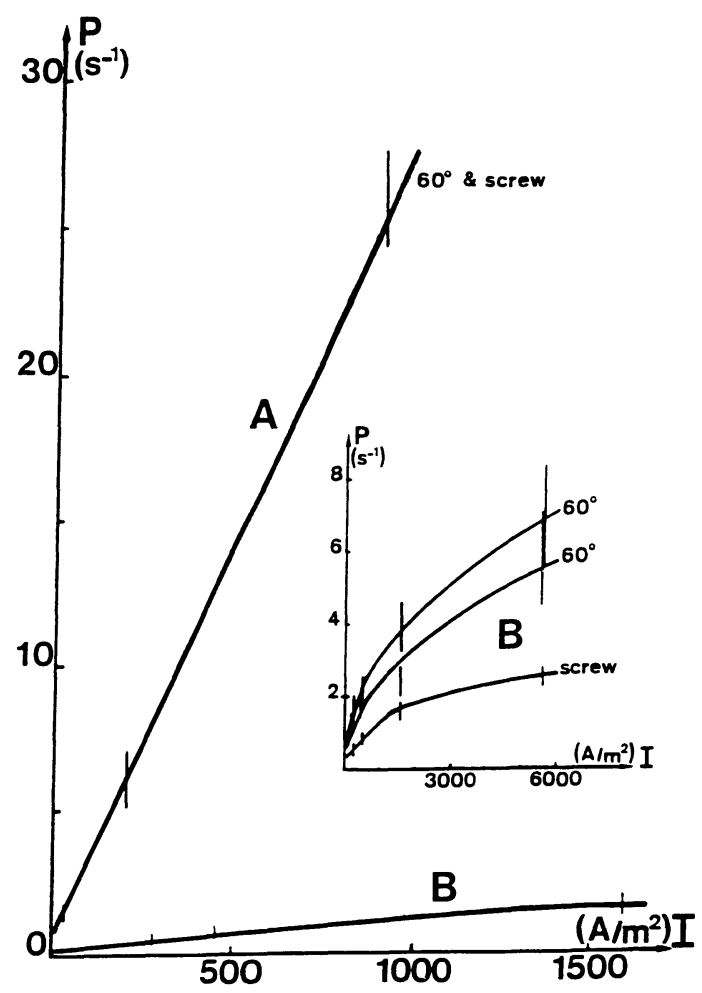

Fig. 7. - Cathodoplastic effect in ZnS: $P=\mathrm{d} V / \mathrm{d} L$ versus $I$. A: $T=180^{\circ} \mathrm{C}, \sigma=26 \pm 8 \mathrm{MPa}, \mathrm{B}: T=$ $120{ }^{\circ} \mathrm{C}, \sigma=40 \pm 10 \mathrm{MPa}$. 


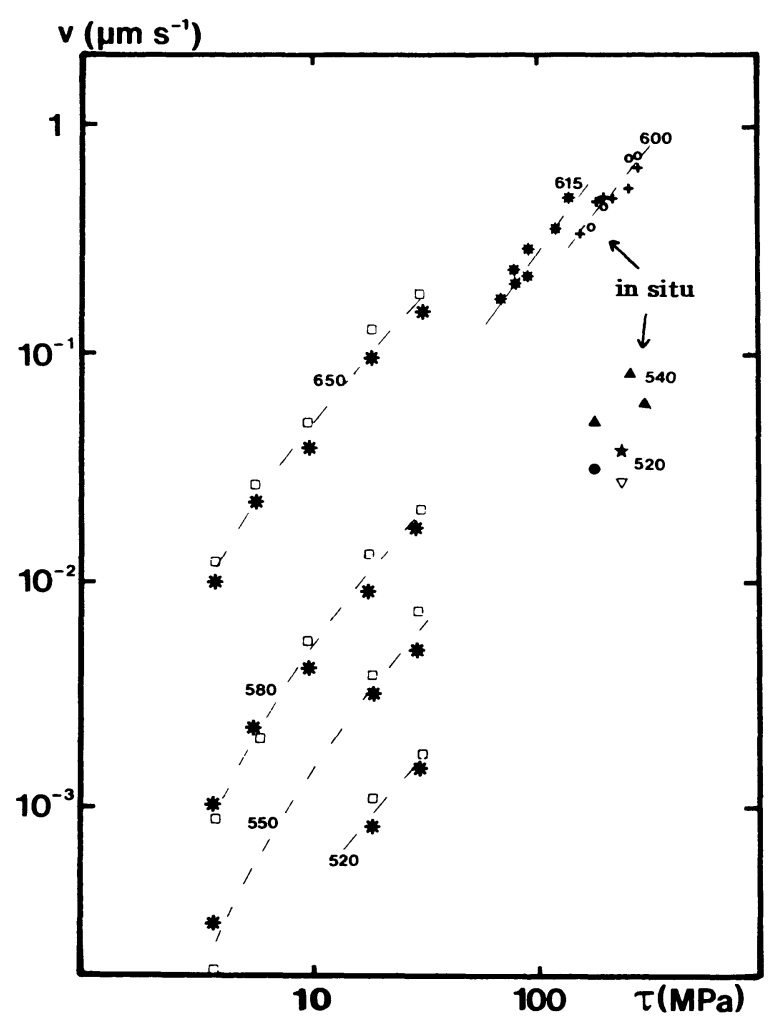

Fig. 8. - Dislocation velocity versus stress in Si. Comparison between the results of in situ experiments in TEM and the results obtained by George by X-ray topography [20] (from [4]). Numbers refer to the test temperature in ${ }^{\circ} \mathrm{C}$.

easily measurable (this is a kind of "anthropic visibility criterion"). Since the velocities scale as $\exp (-(F(\sigma)+W) / k T)$ or $\exp (-(1 / 2 F(\sigma)+W) / k T)$ depending on the velocity regime (Eqs. (4) and (5)), in materials where $W_{\mathrm{m}}$ is smaller, $F(\sigma)$ has to be increased (by setting $\sigma$ down to lower values). The mean free path of a kink pair $X=2 b \exp (F(\sigma) / 2 k T)$ is then found significantly larger, as observed.

Considering the dissociation into partials, the lower velocity found for $60^{\circ}$ dislocations in $\mathrm{Ge}$ as compared to screws suggest that the $90^{\circ}$ partial of the $60^{\circ}$ dislocation is rate controlling. Table II shows that kink formation energies on screws and $60^{\circ}$ dislocations are similar, but that $W_{\mathrm{m}}\left(60^{\circ}\right)>$ $W_{\mathrm{m}}$ (screw).

In III-V compounds, $V(\alpha)>>V(\beta)=V$ (screw). This effect largely overwhelms the difference between screws and $60^{\circ}$ velocities observed in Ge. Looking again at core structures, the common partial dislocation belonging to both screws and $\beta$ dislocations is the $30^{\circ} \beta$ partial, whose core is made of (non reconstructed) A atoms, and which should be the rate controlling dislocation. An alternative possibility [5] is that $\alpha$ partials (B core atoms) are slightly understoechiometric, due to the larger vapour pressure of the higher valency B elements, and that the resulting vacancy sites can help both kink pair formation and kink motion (broken bonds).

High energy electrons can enhance dislocation motion through the production of electron-hole pairs, which recombine preferentially at dislocations [16]. It is considered $[17,18]$ that lattice vibrations induced by non-radiative capture could greatly enhance the nucleation and/or the migration 


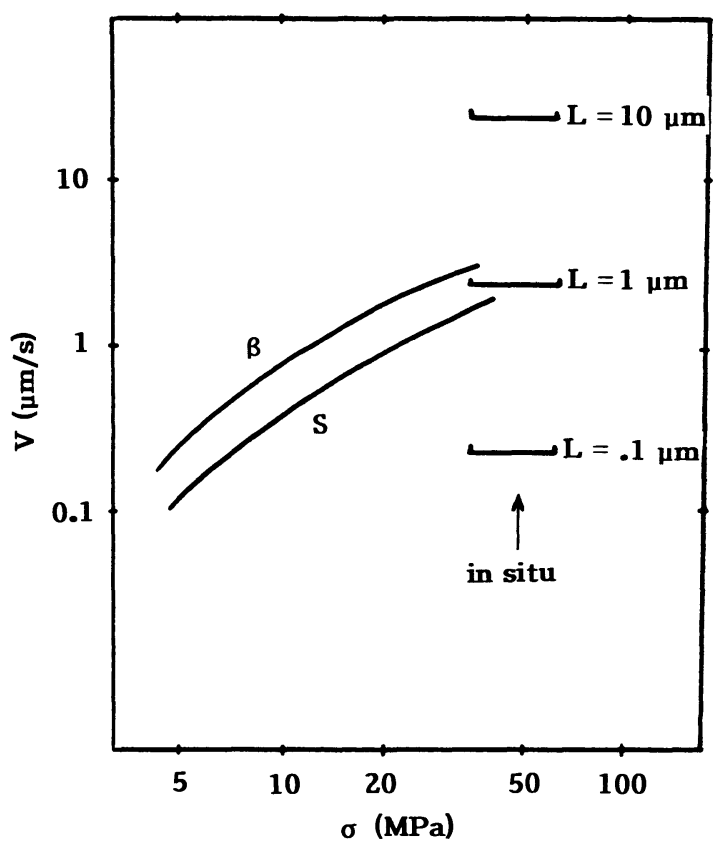

Fig. 9. - Dislocation velocity versus stress in InSb. Comparison between the results of in situ experiments in TEM (Fig. 3) and the results of double etch pits of Erofeeva and Osip'Yan [22]. The velocity for $L=10 \mu \mathrm{m}$ has been extrapolated from the results of figure 3 taking into account the high value of $X$ in InSb [13].

of kinks through the reduction of the corresponding energies. The recombination energy is supposed to increase with the band gap: this could explain why the cathodoplastic effect is larger in materials with a larger band gap, like $\mathrm{ZnS}$.

The results presented here provide for the first time evidence of an enhancement of dislocation glide by electron excitation in the length effect regime of dislocation velocities $(X>>L)$. They indicate that friction forces are larger without excitation, since dislocations are considerably slowed down as the electron beam intensity is reduced. A theoretical analysis shows that the observed reduction in activation energy is related to the electronic energy level associated with straight dislocations (and not with kinks) $[15,18]$. The energy released upon capture $(\Delta E)$ assists the initial kink pair formation. In $\mathrm{ZnS}$, we estimate $\Delta E=0.65 \pm 0.3 \mathrm{eV}$.

Finally, the observed variation of $P=\mathrm{d} V / \mathrm{d} L$ with I can be qualitatively explained in terms of the general theory of recombination enhanced defect motion: it is generally assumed that the recombination rate is proportional to the electron-hole pair generation rate, which is itself proportional to the electron-beam intensity $[17,18]$. However, Sumi [19] pointed out the possibility of a saturation of the radiation enhanced defect reaction rate at high levels of injection currents (i.e. high electron beam intensity in the present case).

\section{Conclusion.}

In situ straining experiments have been applied to elemental and to compound semiconductors to study dislocation mobilities. The scale reached by these experiments is complementary to that of other techniques, and allowed a thorough determination of formation and migration energies of 
kinks through combined measurements of dislocation velocities and of mean free paths of kinks. The different velocities of screws and of $60^{\circ}$ dislocations in elemental semiconductors and of $\alpha$ dislocations as compared to $\beta$ and screws in compounds have been discussed in terms of dislocation core structures. A cathodoplastic effect has also been observed in some compounds, in relation with the width of the energy gap. Other mechanisms such as twinning or photoplastic effect should worth being investigated by this technique.

\section{References}

[1] Louchet F. and George A., J. Phys., Paris, 9 (1983) C4-51.

[2] HiRTH J.P. and LOTHE J., Theory of Dislocations (New York: Mc Graw Hill, 1968).

[3] GotTsChalk H., J. Phys., Paris, 9 (1983) C4-69.

[4] LOUCHET F., Phil. Mag. A 43 (1981) 1289.

[5] Louchet F. and ThiBAult-DESSEAUX J., R. Phys. Appl. 22 (1987) 207.

[6] LouCheT F. Microsc. Semiconducting Mater. Eds. A.G. Cullis and D.C. Joy, Inst. Phys. Conf. Ser. $\mathrm{N}^{\circ} 60$ (London, Bristol: The Institute of Physics, 1981) p. 35.

[7] Hirsch P.B., Ourmazd A. and Pirouz P., Micros. Semiconducting Mater. Eds. A.G. Cullis and D.C. Joy, Inst. Phys. Conf. Ser. $N^{\circ} 60$ (London, Bristol: The Institute of Physics, 1981) p. 29.

[8] Louchet F., Cochet-muchy D., Brechet Y. and Pelissier J., Phil. Mag. A 57 (1988) 327.

[9] Fnaiech M., Reynaud F., Couret A. and Caillard D., Phil. Mag. $A 55$ (1987) 405.

[10] Caillard D., Clement N., Couret A., Androussi Y., Lefebvre A. and Vanderschaeve G., a) Microsc. Semiconducting Mater. Eds. A.G. Cullis and D.C. Joy, Inst. Phys. Conf. Ser. $\mathrm{N}^{\circ} 87$ (London, Bristol: The Institute of Physics, 1987) p. 361; b) ibid. N$^{\circ} 100$ (1989) p. 403.

[11] Zafrany M., Voillot F., Peyrade J.P., Caillard D., Couret A. and Cocquille R., Phil. Mag A 65 (1992) 195.

[12] GAUFFIER J.L., Ph.D. Thesis, INSA Toulouse (1992).

[13] Levade C., CouderC J.J., CAillard D. and Couret A., Electron Microsc. Plasticity Fracture Research Mater. Eds. U. Messerschmidt, F. Appel, J. Heydenreich and V. Schmidt (Berlin: Akad. Verlag, 1990) p. 199.

[14] LeVAde C., VANDerschaeve G., Couderc J.J., FAREss A. and CAIllard D.: Microsc. Semiconducting Mater. Eds A. Cullis and N. Long, Inst. Phys. Conf. Ser. $n^{\circ} 117$ (London, Bristol: The Institute of Physics) p. 143.

[15] Vanderschaeve G., Levade C., Faress A., Couderc J.J. and Caillard D., J. Phys. IV (Paris, 1991) 1, C 6-305.

[16] Ourmazd A., Weber E., Gottschalk H., Booker G.R. and AleXAnder H., Microsc. Semiconducting Mater. Eds. A.G. Cullis and D.C. Joy, Inst. Phys. Conf. Ser. $\mathrm{N}^{\circ} 60$ (London, Bristol: The Institute of Physics, 1981) p. 63.

[17] MAeda K. and TAKeUChi S.: J. Phys. Paris 44 (1983) C4-375.

[18] Maeda N., TAKeuchi S., Structure and Properties of Dislocations in Semiconductors, Eds. S.G. Roberts, D.B. Holt and P.R. Wilshaw, Inst. Phys. Conf. Ser. $n^{\circ} 104$ (London, Bristol: The Institute of Physics) p. 303.

[19] Sumi H., Phys. Rev. B 29 (1986) 4616.

[20] GEORGE A., Ph.D. Thesis, University of Nancy, 1977.

[21] Erofeeva S.A. and OSIP’YAN YU A., Sov. Phys. Sol. State 15 (1973) 538 and 16 (1975) 2076. 